\title{
Introduction: The geologic mapping of Vesta
}

\author{
David A. Williams*, R. Aileen Yingst, W. Brent Garry \\ School of Earth E Space Exploration, Arizona State University, Tempe, AZ 85287-1404, United States \\ Planetary Science Institute, Tucson, AZ 85719, United States \\ NASA Goddard Spaceflight Center, Greenbelt, MD 20771, United States
}

\section{A R T I C L E I N F O}

\section{Article history:}

Received 15 November 2013

Revised 3 March 2014

Accepted 3 March 2014

Available online $\mathrm{xxxx}$

\section{Keywords:}

Asteroid Vesta

Asteroids, surfaces

Geological processes

\begin{abstract}
A B S T R A C T
The purpose of this paper is to introduce the Geologic Mapping of Vesta Special Issue/Section of Icarus, which includes several papers containing geologic maps of the surface of Vesta made to support data analysis conducted by the Dawn Science Team during the Vesta Encounter (July 2011-September 2012). In this paper we briefly discuss pre-Dawn knowledge of Vesta, provide the goals of our geologic mapping campaign, discuss the methodologies and materials used for geologic mapping, review the global geologic context of Vesta, discuss the challenges of mapping the geology of Vesta as a small airless body, and describe the content of the papers in this Special Issue/Section. We conclude with a discussion of lessons learned from our quadrangle-based mapping effort and provide recommendations for conducting mapping campaigns as part of planetary spacecraft nominal missions.
\end{abstract}

(c) 2014 Elsevier Inc. All rights reserved.

\section{Introduction}

In July 2011 NASA's Dawn spacecraft arrived in orbit around the main belt asteroid (4) Vesta, beginning a more than year-long orbital study of this unique protoplanet (Russell and Raymond, 2011; Russell et al., 2012). The Dawn spacecraft studied Vesta with three instruments: a German-built Framing Camera (FC: Sierks et al., 2011), an Italian-built visible and infrared spectrometer (VIR: De Sanctis et al., 2011), and an American-built gamma ray and neutron detector (GRaND: Prettyman et al., 2011). The spacecraft's radio communications system also conducted a gravity experiment (Raymond et al., 2013). A geologic mapping campaign was developed as part of the Nominal Mission to provide a systematic, cartography-based initial characterization of the global and regional geology of Vesta. The intent of the geologic mapping campaign was twofold: (1) provide geologic and stratigraphic context for analysis by the Science Team, and (2) inform the broader science community about the evolving perspectives regarding the geology of Vesta during the mission timeline. The purpose of this introductory paper is to highlight major aspects of the geologic mapping campaign for Vesta, while simultaneously reducing the amount of replicated information in each of the papers in this Special Issue/Section. Herein we include a brief summary of pre-Dawn

\footnotetext{
* Corresponding author at: School of Earth \& Space Exploration, Box 871404, Arizona State University, Tempe, AZ 85287-1404, United States. Fax: +1 480965 8102.

E-mail address: david.williams@asu.edu (D.A. Williams).
}

knowledge of physiography and geologic character of Vesta, discuss the goals of the mapping effort, and summarize the basemap and ancillary materials as well as the methodologies used in the Vesta quadrangle-based mapping effort. We then present the global geologic context for the quadrangle mapping effort, discuss the challenges that arose in the mapping of a relatively small airless body like Vesta, and briefly describe the content of the other papers in this Special Issue. We conclude with a list of lessons learned that future mission teams should review when designing a geologic mapping program to aid in the analysis of data during the nominal mission. The goal of this paper is not to provide a full document of background elements (these are described in part in previously published papers) but to help establish a coherent context for the topical geologic mapping papers that follow. Information relevant to mapping efforts or interpreted geology of specific quadrangles is presented directly in the following papers, as necessary.

\section{Background: the importance of Vesta}

The inner Main Belt Asteroid (4) Vesta was discovered by H.W. Olbers in 1807 (see review by Pilcher, 1979) and orbits the Sun at a mean heliocentric distance of 2.36 astronomical units (AU) with an eccentricity of 0.097 (Williams, 1989). Hubble Space Telescope (HST) observations showed that Vesta is a triaxial ellipsoid with a flattened south polar region (Thomas et al., 1997a). Subsequent measurements by the Dawn spacecraft show that Vesta has radii of $286.3 \mathrm{~km} \times 278.6 \mathrm{~km} \times 223.2 \mathrm{~km}( \pm 0.1 \mathrm{~km})$, a mean radius of 
$262.7 \pm 0.1 \mathrm{~km}$, a volume of $\sim 7.497 \times 10^{7} \mathrm{~km}^{3}$, a mass of $2.59 \times 10^{20} \mathrm{~kg}$, and a bulk density of $3456 \pm 35 \mathrm{~kg} / \mathrm{m}^{3}$ (Russell et al., 2012). Vesta's surface gravitational acceleration is $\sim 0.25 \mathrm{~m} /$ $\mathrm{s}^{2}$ (Konopliv et al., in press; Ermakov et al., submitted for publication). Visible and near-IR reflectance spectroscopy from Earthbased telescopes showed the surface of Vesta exhibits absorption features indicative of basaltic minerals, and that Vesta is similar in surface mineralogy to the howardite-eucrite-diogenite (HED) family of basaltic achondrite meteorites (e.g., McCord et al., 1970; Feierberg et al., 1980; Gaffey, 1997; Binzel et al., 1997; Cochran and Villas, 1998; Reddy et al., 2010), as determined from laboratory studies (McSween et al., 2011 and references therein). Spectral and elemental analyses of Vesta on Dawn-derived data are consistent with the link between Vesta and the HED meteorites (De Sanctis et al., 2012a; Reddy et al., 2012a; Prettyman et al., 2012; McSween et al., 2013).

Globally from HST data Vesta appeared to have a high albedo eastern hemisphere and a lower-albedo western hemisphere (Binzel et al., 1997); the only physiographic feature that was observed was interpreted to be a south polar impact basin with a central peak (Thomas et al., 1997a; 1997b). Subsequent Dawn observations indicate there are actually two large basins in the vicinity of the vestan south pole: the younger Rheasilvia basin ( $500 \pm 25 \mathrm{~km}$ diameter, $19 \pm 5 \mathrm{~km}$ deep), and the older Veneneia basin ( $400 \pm 25 \mathrm{~km}$ diameter, $12 \pm 2 \mathrm{~km}$ deep: Schenk et al., 2012). These impact basins are interpreted to have exposed diogenitic material, perhaps ejecting the HED meteorites (see De Sanctis et al., 2012a; McSween et al., 2013 and references therein). Dawn VIR data supports an interpretation that the Rheasilvia basin floor is composed of low-Ca, Mg pyroxenes with no obvious olivine signature (De Sanctis et al., 2012a). Additionally, isotopic geochemical studies on the HED meteorites suggest the heating, melting, fractionation, extrusion, and solidification of the basaltic crust on Vesta occurred within the first 10 myr of Solar System history (Lugmair and Shukolyukov, 1998; Srinivasan et al., 1999; Nyquist et al., 2001), and that volcanism on Vesta ended between 10 and $100 \mathrm{Ma}$ after formation (Schiller et al., 2010; McSween et al., 2011). Thus, Vesta is an ideal object to study the early differentiation and other proto-planetary processes that occurred in the early Solar System.

\section{Geologic mapping of Vesta}

Geologic maps serve as tools to understand the evolution of the terrestrial planets and satellites (Carr et al., 1976, 1984; Greeley and Carr, 1976; Wilhelms, 1990; Hansen, 2000; Tanaka et al., 2010). The overarching goal of geologic maps is to place observations of surface features into their stratigraphic context to develop a sequence of events for the evolution of planetary surfaces (see Carr et al., 1976). Relative stratigraphic dating and estimation of ages from impact crater populations have proven useful in understanding the geologic evolution of many planetary bodies, including several asteroids (Carr et al., 1994; Veverka et al., 1994; Chapman et al., 1999, 2002; Marchi et al., 2010, 2012a).

The advantage of geologic mapping over photogeologic analyses alone is that it reduces the complexity of heterogeneous planetary surfaces into comprehensible portions. Discrete material units are defined and characterized based upon specific physical attributes related to the geologic processes that are interpreted to have produced them. The distributions of these units are then mapped, along with structural and morphologic features, in order to identify the relative roles of various geologic processes in shaping their surfaces. Geologic mapping has been applied to most terrestrial planets and outer planet satellites for which adequate imaging coverage is available. The nature of planetary surfaces must be interpreted within the context of the endogenic and exogenic geologic processes that resulted in their present state. The relative roles of these two broad classes of geologic processes can be assessed from stratigraphic studies. The smaller asteroids studied prior to the Dawn mission (e.g., Gaspra, Ida, Eros, Lutetia) appear to have been dominated by impact processes, with some evidence of minor tectonic and erosional-depositional processes (e.g., Sullivan et al., 2002; Massironi et al., 2012). The paucity of non-impact geologic processes on small asteroids is a consequence of their small size and resulting inability to retain atmospheres, and the small masses of such bodies inhibited internal differentiation, development of internal dynamos, volcano-tectonic activity, and corresponding active surficial geologic processes that would erase parts of their cratering record (as seen on the Moon or Mars). Importantly, Vesta is a much larger asteroid for which meteoritic and spectroscopic evidence suggests past differentiation and volcanic activity (e.g., Wilson and Keil, 1996; McSween et al., 2011), and is an intermediate case between the planets and other smaller asteroids studied to date. Therefore Vesta is an ideal small body where we can employ traditional geologic mapping methods in order to help derive a regional to global geologic history and place other observations into a comparable context.

\subsection{Goals of the Vesta mapping effort}

The Dawn Science Team planned to produce cartographic products of Vesta from the FC images, including global, hemispheric, and polar mosaics, as well as 15 regional quadrangles (Fig. 1, Table 1, see also Roatsch et al., 2012a). In addition to our efforts to globally map Vesta at 1:500,000 scale during the Nominal Mission (Yingst et al., in press), we (the authors, all Dawn Participating Scientists) were recruited to manage the generation of 15 quadrangle geologic maps at 1:250,000 scale. These were based on the quadrangle scheme employed by DLR for the compilation of cartographic products for the Dawn Science Team. The goal of the Vesta global mapping effort was to use iterative geologic mapping of increasingly higher spatial resolution FC images obtained at each orbital phase of the Dawn mission to (1) support the Geosciences Working Group by providing geologic and stratigraphic context of surface features, and (2) to provide geologic context for the analysis of data from the Visible and Infrared Spectrometer (VIR) and the Gamma Ray and Neutron Detector (GRaND). In contrast to the global mapping effort, the goal of the quadrangle mapping effort was to improve upon the geologic history identified by the global map (made with lower resolution Survey and High Altitude Mapping Orbit (HAMO) data) using Low Altitude Mapping Orbit (LAMO) data to identify major types of surface features, geologic units, and stratigraphic relations at regional and local scales. Quadrangle-based geologic mapping was intended to be driven by the science questions and hypotheses that arose during global mapping efforts.

As initially planned, geologic mapping was performed using the major cartographic products produced by the German Aerospace Center (DLR) as base maps, including global and quadrangle FC mosaics (see Roatsch et al., 2012a). This approach was markedly different from geologic mapping of other planetary bodies for several reasons. First, geologic mapping of Vesta was conducted during the data acquisition phase of a mission (a formalized geologic mapping program is generally instituted near the end of a mission). Second, the geologic mapping efforts were conducted primarily to aid in the interpretation of geochemical and spectral data while they were being acquired. Third, and finally, Vesta geologic mapping efforts were conducted using static quadrangle boundaries that were established prior to the start of the Dawn Nominal Mission (i.e., before we had a complete understanding of what the physiographic, geologic, and stratigraphic character of the body). 

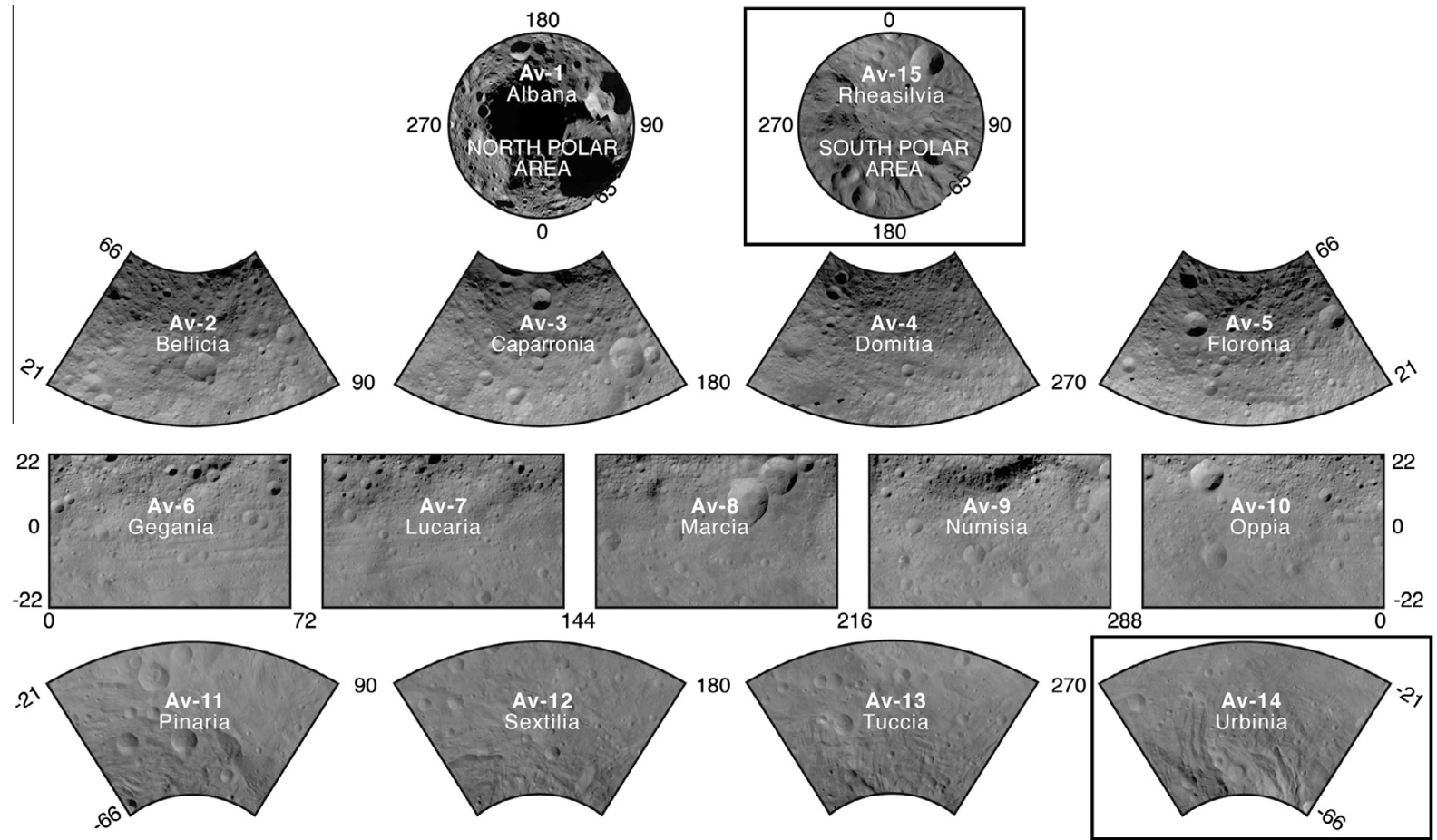

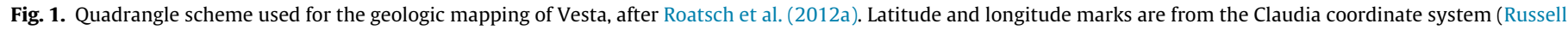

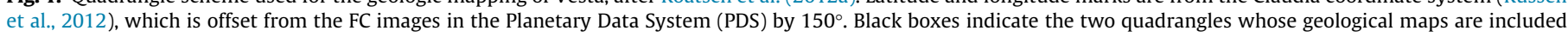
with this paper (See also Supplemental online material).

Table 1

Summary of Vesta mapping quadrangles. Refer to Fig. 1.

\begin{tabular}{|c|c|c|c|}
\hline Quad \# & Quad name & Mappers & Major features \\
\hline Av-1 & Albana & D.T. Blewett, D.L. Buczkowski & Vesta $\mathrm{N}$ pole, Rheasilvia basin antipode, possible antipodal terrain \\
\hline Av-2 & Bellicia & O. Ruesch, H. Hiesinger ${ }^{\mathrm{a}}$ & Heavily cratered terrain, Bellicia crater w/olivine signature \\
\hline Av-3 & Caparronia & J.E.C. Scully, D.T. Blewett & Heavily cratered terrain \\
\hline Av-4 & Domitia & J.E.C. Scully & Saturnalia Fossae troughs, heavily cratered terrain \\
\hline Av-5 & Floronia & J.E.C. Scully, D.A. Williams & Heavily cratered terrain \\
\hline Av-6 & Gegania & L. LeCorre, M. Schäfer, A. Nathues & Divalia Fossae troughs, Rheasilvia ejecta (distinctive 'lane' in false color images) \\
\hline Av-7 & Lucaria & L. LeCorre, M. Schäfer, A. Nathues & Lucaria Tholus, Octavia ejecta, Divalia Fossae troughs \\
\hline Av-8 & Marcia & D.A. Williams & Large craters Marcia and Calpurnia, Aricia Tholus, Octavia crater w/distinctive diffuse ejecta \\
\hline Av-9 & Numisia & D.L. Buczkowski & Vestalia Terra crustal highland \\
\hline Av-10 & Oppia & W.B. Garry & Oppia crater $\mathrm{w} /$ distinctive diffuse ejecta \\
\hline Av-11 & Pinaria & T. Hoogenboom, K. Krohn & Rheasilvia basin rim scarp, ejecta on basin floor \\
\hline Av-12 & Sextilia & K. Krohn & Rheasilvia basin rim scarp, ejecta on basin floor \\
\hline Av-13 & Tuccia & T. Kneissl & Rheasilvia ejecta on basin floor, several young, fresh craters \\
\hline Av-14 & Urbinia & S.C. Mest & Rheasilvia ridge-and-groove terrain \\
\hline Av-15 & Rheasilvia & R.A. Yingst, S.C. Mest & Rheasilvia basin central peak \\
\hline
\end{tabular}

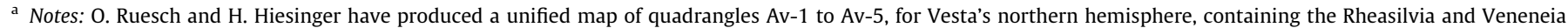
antipodes. See Ruesch et al. (2014).

This last point was a concern for us, as it was unclear whether the pre-determined quadrangle boundaries and scales would effectively support the identification and interpretation of geologic features. In short, it was unclear whether there would be sufficient geologic diversity and accompanying science drivers to warrant 15 individual quadrangle maps. This point is discussed in more detail in subsequent sections.

As the global mapping of the lower spatial resolution data sets (Approach, FC resolution $>50-1 \mathrm{~km} /$ pixel and Survey, FC resolution of $260 \mathrm{~m} /$ pixel) proceeded through the summer and fall of 2011, global units were defined (Yingst et al., 2011), and a series of geologic "sketch" maps of the whole body and the 15 quadrangles were presented at the Fall American Geophysical Union (AGU) Meeting in San Francisco in December 2011. As HAMO and LAMO data became available, refined versions of the maps were presented at the Lunar and Planetary Science Conference in March
2012. A Dawn Vesta Mappers' Meeting was held at Brown University in June 2012 to re-assess the mapping approaches, refine the global mapping framework, and identify how global map units could be subdivided into related quadrangle map units, taking advantage of the higher resolution LAMO images. It was assumed that the higher resolution afforded by the LAMO images would enable more regionally representative geologic mapping by helping to narrow the range of interpretations for geologic units first identified at global scale. This approach was successful, and this Special Issue/Section presents the results of these regional mapping efforts.

\subsection{Vesta mapping tools: basemaps and supplemental data}

The Dawn mission was designed to consist of three orbital phases, each favoring one of the three instruments (Russell and 
Raymond, 2011). The Survey orbit ( $\sim 2700 \mathrm{~km}$ altitude, FC resolution of $260 \mathrm{~m} /$ pixel) was optimized to collect global data for the VIR spectrometer for mineralogical characterizations. The HAMO orbit ( $685 \mathrm{~km}$ altitude, FC resolution of $70 \mathrm{~m} /$ pixel) was optimized for the FC to obtain high-resolution data for assessment of geologic features and stereo topography. The LAMO orbit (200 km altitude, FC resolution of $20-25 \mathrm{~m} /$ pixel) was optimized for the GRaND instrument to obtain the highest resolution data on elemental abundances of the surface. However, mission duration, data storage, and downlink resources were such that FC imaging was possible during all three orbital phases, enabling increasingly higher spatial resolution images to be obtained and allowing iterative geologic mapping across the mission timeline. In addition, improved photometry and calibrations obtained during the mission enabled quality improvements in the FC images and mosaics, including photometrically corrected versions that were useful to separate low albedo materials from shadowed terrain. Given all of these resources, the quadrangle-based geologic mapping efforts used a common FC image base map, which replaced the lower resolution products with successively higher resolution $(200,70$, $20 \mathrm{~m} /$ pixel for Survey, HAMO, and LAMO orbits, respectively) products as the Dawn at Vesta mission proceeded (Fig. 2a-d).

Global mapping began using Rotational Characterization (RC) observations during Dawn's Approach phase (Yingst et al., in press), which returned images primarily from the south polar region. The first near-global geologic map was made from Survey orbit FC image mosaics (Jaumann et al., 2012), covering all longitudes from $90^{\circ} \mathrm{S}$ to about $45^{\circ} \mathrm{N}$, with a spatial resolution of $\sim 260 \mathrm{~m} /$ pixel and registered to the HST Digital Terrain Model (DTM). Later, as HAMO base maps of the quadrangles became available, detailed quadrangle mapping began using the $70 \mathrm{~m} /$ pixel base maps registered to the FC Survey orbit-based DTM (Fig. 2a). Once the LAMO basemaps (spatial resolution $25 \mathrm{~m} /$ pixel) were produced and registered to a HAMO DTM (Fig. 2b: Preusker et al., in preparation), these became the final basemap products used to complete the quadrangle maps. Other supplemental materials, including the photometrically corrected FC HAMO mosaics (Fig. 2c), FC false color ratio images (Table 2; Fig. 2d: Reddy et al., 2012a,b), and FC topographic maps (Fig. 3), slope, and contour maps derived from the various DTMs aided the geologic mapping and interpretations. Additional coverage of the northern hemisphere quadrangles $\left(>45^{\circ} \mathrm{N}\right)$ was obtained during HAMO-2 at lower resolution $(70 \mathrm{~m} /$ pixel) near the end of the Vesta Nominal Mission. Basic compositional information (e.g., relative strength of pyroxene bands, $\mathrm{OH}$ abundance) from the VIR and GRaND instruments (De Sanctis et al., 2012a,b; Prettyman et al., 2012) assisted with the identification and interpretation of geologic units that displayed distinctive albedo and/or color.

\subsection{Vesta mapping techniques}

For each quadrangle, mappers assembled the base map image mosaics, DTMs, and other supplemental materials using ArcGISTM10 software (ESRI, 2011), which facilitated a consistent approach to geologic mapping (e.g., map scales and symbols; see Tanaka et al., 2010). Each quadrangle mapper adapted and refined the units defined in the global geologic map by Yingst et al. (in press) using the higher spatial resolution LAMO base maps as well as the supplemental data. The quadrangle mappers collaborated with the mappers of contiguous quadrangles in order to assure unit contacts matched across quadrangle boundaries, that similar units were used, and that a consistent level of detail in the mapping was maintained (e.g., mapping craters down to the same size, $2 \mathrm{~km}$ diameter, although craters down to $6 \mathrm{~km}$ diameter are the limit visible on the published maps due to scaling issues).

\subsection{Vesta global geologic context for the quadrangles}

Globally, Vesta can be divided into distinct units (Yingst et al., in press): (1) the south polar and southern latitude, relatively lightlycratered floors of the Rheasilvia and Veneneia impact basins (called the Rheasilvia Formation), including central peak, ridged and grooved, and smooth units; (2) the equatorial, highly-cratered ridge and trough-bearing unit called the Divalia Fossae Formation; (3) an equatorial, highly-cratered unit lacking the equatorial troughs that is located on a regional topographic highland named Vestalia Terra; and (4) the high northern latitude and north polar, heavily-cratered unit containing subdued ridges and troughs called the Saturnalia Fossae Formation. Heavily cratered units lacking ridges and troughs in other locations are mapped as cratered highlands. Across Vesta, younger bright and dark-rayed craters and their ejecta fields are superposed upon all of these units.

The quadrangle-based geologic maps were intended to directly support data analysis by the Dawn Science Team during the Nominal Mission by providing a consistent and updated context for observations and interpretations. Thus, all of the geologic maps in the papers of this Special Issue/Section are presented as figures rather than large-format geologic maps at a specified map scale. All 15 quadrangle maps, at 1:250,000 scale, are included as Supplementary Online Material in this Special Issue. Material units and structural features are described in the text of each paper and in stratigraphic order, so that units of associated terrains are grouped together, and descriptions are followed by interpretations of each unit.

Impact crater statistical techniques and application of cratering model ages for Vesta in these mapping papers utilize either one or both of two chronology systems developed by the Dawn Science Team. The chronology system developed by Schmedemann et al. (submitted for publication) adapts the lunar cratering chronology to Vesta (see Appendix A.1 for a detailed summary), whereas the asteroid flux-derived chronology developed by Marchi et al. (2012b) and O'Brien et al. (submitted for publication) is based on dynamical studies of the main asteroid belt over its history (see Appendix A.2 for a summary). A comparison of the cratering model ages resulting from these two chronology systems is discussed in section 7 of O'Brien et al. (submitted for publication); both systems give comparable ages back to $\sim 3.5 \mathrm{Ga}$, where the two systems diverge. The lunar-derived chronology tends to estimate older ages for more heavily cratered surfaces than the asteroid flux-derived chronology. For example, the age of the Rheasilvia basin is estimated to be $\sim 1$ Ga from asteroid flux-derived chronology (Schenk et al., 2012; Marchi et al., 2012a; O'Brien et al., submitted for publication) versus an estimated age of $\sim 3.5 \mathrm{Ga}$ from the lunar-derived chronology (Schmedemann et al., submitted for publication). Because of these differences, quadrangle mappers were recommended to include cratering model ages from both chronology systems in their mapping papers. However, the role of these techniques in this Special Issue/Section varies from paper to paper according to the subject of the study. For a detailed understanding of application of crater size-frequency distributions to Vesta, the reader is directed to the "Cratering on Vesta" Special Issue of Planetary and Space Science (in press), and specifically the papers by Marchi et al. (2014, in press) and O'Brien et al. (submitted for publication) on the asteroid flux-derived Vesta chronology, and by Schmedemann et al. (submitted for publication) on the lunarderived Vesta chronology.

\subsection{Challenges of Vesta as a geologic mapping target}

The delineation, description, and interpretation of geologic and stratigraphic features on Vesta is significantly more complicated than similar mapping efforts on other terrestrial bodies for several 
(a)
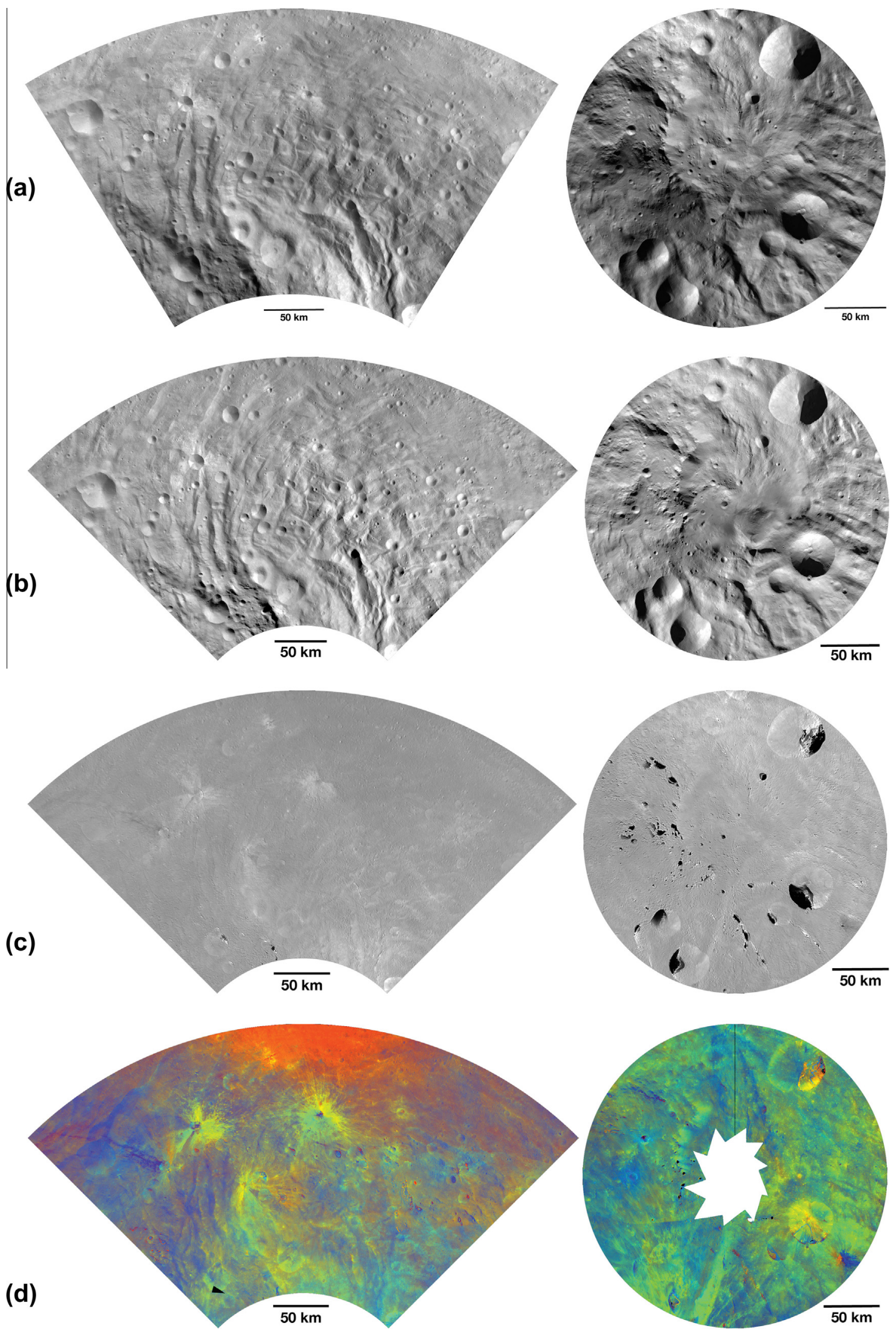

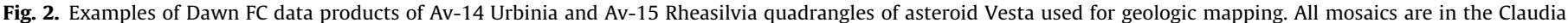

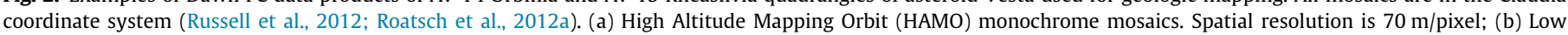

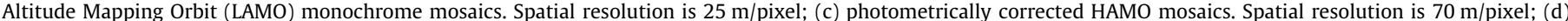
HAMO-derived Clementine-type color ratio mosaics. Spatial resolution is $70 \mathrm{~m} /$ pixel. Colors correspond to Red: $750 / 430 \mathrm{~nm}$, Green: $750 / 920 \mathrm{~nm}$, and Blue $430 / 750 \mathrm{~nm}$. 
Table 2

Information on Dawn FC Clementine-type color ratio images.

\begin{tabular}{|c|c|c|}
\hline Channel & $\begin{array}{l}\text { FC ratio } \\
\text { image }\end{array}$ & Compositional interpretation \\
\hline Red & $750 / 440 \mathrm{~nm}$ & Shows steeper visible spectral slope \\
\hline Green & $750 / 920 \mathrm{~nm}$ & $\begin{array}{l}\text { Shows mafic mineral absorption band depth (i.e., an indicator of iron abundance, particle size effects, space weathering, and geometry } \\
\text { mixing of minerals) }\end{array}$ \\
\hline Blue & $440 / 750 \mathrm{~nm}$ & Inverse of Red channel: Shows weaker spectral slope than average surface \\
\hline
\end{tabular}

References: Le Corre et al. (2011, 2012), Reddy et al. (2012a,b).

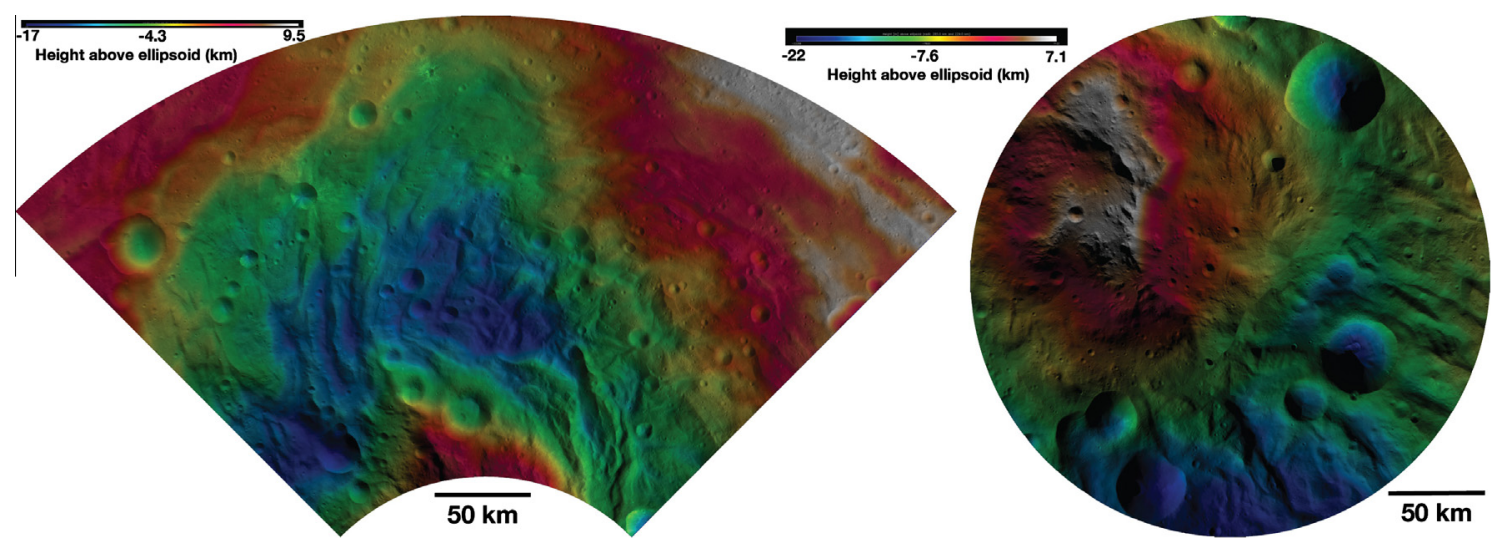

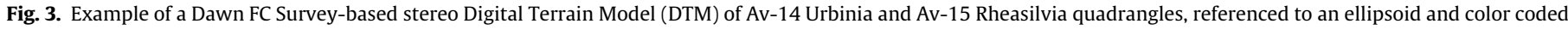

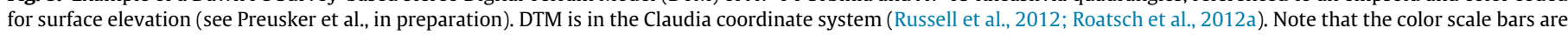
not linear and are different for each quadrangle.

reasons. Primarily, Vesta's ratio of surface relief to radius is $\sim 15 \%$, compared to $\sim 1 \%$ for the Moon and Mars (Jaumann et al., 2012). This means that extremely steep slopes are common on Vesta compared with previously mapped terrestrial planets. These steep slopes may cause impact craters to be deformed into an asymmetric shape (see Krohn et al., 2014). Other craters can be partly buried by subsequent mass movements triggered by later impact events on Vesta's steep slopes. These crater-related processes often make clearly defined contact boundaries between map units very hard or impossible to identify, except for the youngest (freshest) impact materials. Thus, Vesta mappers often use approximate, gradational, or inferred contacts when mapping Vesta's large-scale units at high resolution, except where in contact with young crater materials or at steep scarps. Alternatively, they use dashed lines as "approximate" and denote that approximate means that the contact is not confidently placed due to lack of observation and/or an interpretation that the unit grades due to depositional processes.

Another complication for geologic mapping of Vesta was a lack of non-impact geologic processes, which limits the variety of geological units that can be defined and characterized from images. Thus, most of our quadrangle maps characterize the variety of impact crater-related deposits, including those that have been modified by mass wasting. Many previously studied smaller asteroids are spectrally "bland" (Sullivan et al., 2002) such that there are no composition-related color differences that can aid in map unit definition. Thus we were pleasantly surprised to see strong color and spectral variations on Vesta, which led to better correlation of Dawn compositional data with HED laboratory data and helped confirm the Vesta-HED meteorite association (De Sanctis et al., 2012a,b; McSween et al., 2013; Reddy et al., 2012a).

\subsection{Coordinate system}

The maps presented in this Special Issue/Section use the Claudia coordinate system (see Supplemental material of Russell et al., 2012; Jaumann et al., 2012; Roatsch et al., 2012a,b, 2013), which is so named because it is anchored by the $625 \mathrm{~m}$ Claudia impact crater $\left(-1.6^{\circ}, 356^{\circ}\right.$; see Reddy et al., 2013; Garry et al., 2014). Here we use the Claudia system for all of our geologic maps, to be consistent with our previous studies that are based on the Dawn observations of Vesta, and the cartographic products used as bases for our geologic maps, including the first Survey-based geologic map (Jaumann et al., 2012) and the HAMO-based global geologic map (Yingst et al., in press).

These papers use a different coordinate system from the IAU convention (with which Dawn-supplied data to NASA Planetary Data System (PDS) conform), and the prime meridian in these papers is approximately $150^{\circ}$ eastward from the IAU-PDS convention (Archinal et al., 2011). As of early 2014 data provided to PDS by Dawn use the IAU rotational definition where the right ascension of the prime meridian versus time is given by $285.39^{\circ}+d \times 1617.3329428^{\circ}$, where $d$ is the time in days since Julian day January 12000 . Our papers all use the right ascension of the prime meridian versus time is given by $74.66250^{\circ}+d \times 1617.3331237^{\circ}$ (based on HAMO- 1 and -2 data). The practical difference is the Prime Meridian is approximately $150^{\circ}$ eastward in our current papers from that in PDS data. Readers and data users should always be alert to changes in usage and standards upon which maps are based, as these may change. The data used in the papers in this Special Issue/Section are available in the Claudia coordinate system from the website http://dawndata. igpp.ucla.edu.

\section{Overview of papers in this Special Issue/Section}

This Special Issue/Section contains papers that address specific science topics regarding Vesta geology, in which the quadrangle maps served as tools to address the science questions. There is not one paper for each of the 15 Vesta quadrangles; rather, quadrangle maps were combined where appropriate to better address science questions. For Vesta's northern hemisphere, three papers explore various aspects of the geology. Ruesch et al. (2014) have combined quadrangles Av-1 (Albana), Av-2 (Bellicia), Av-3 (Capar- 


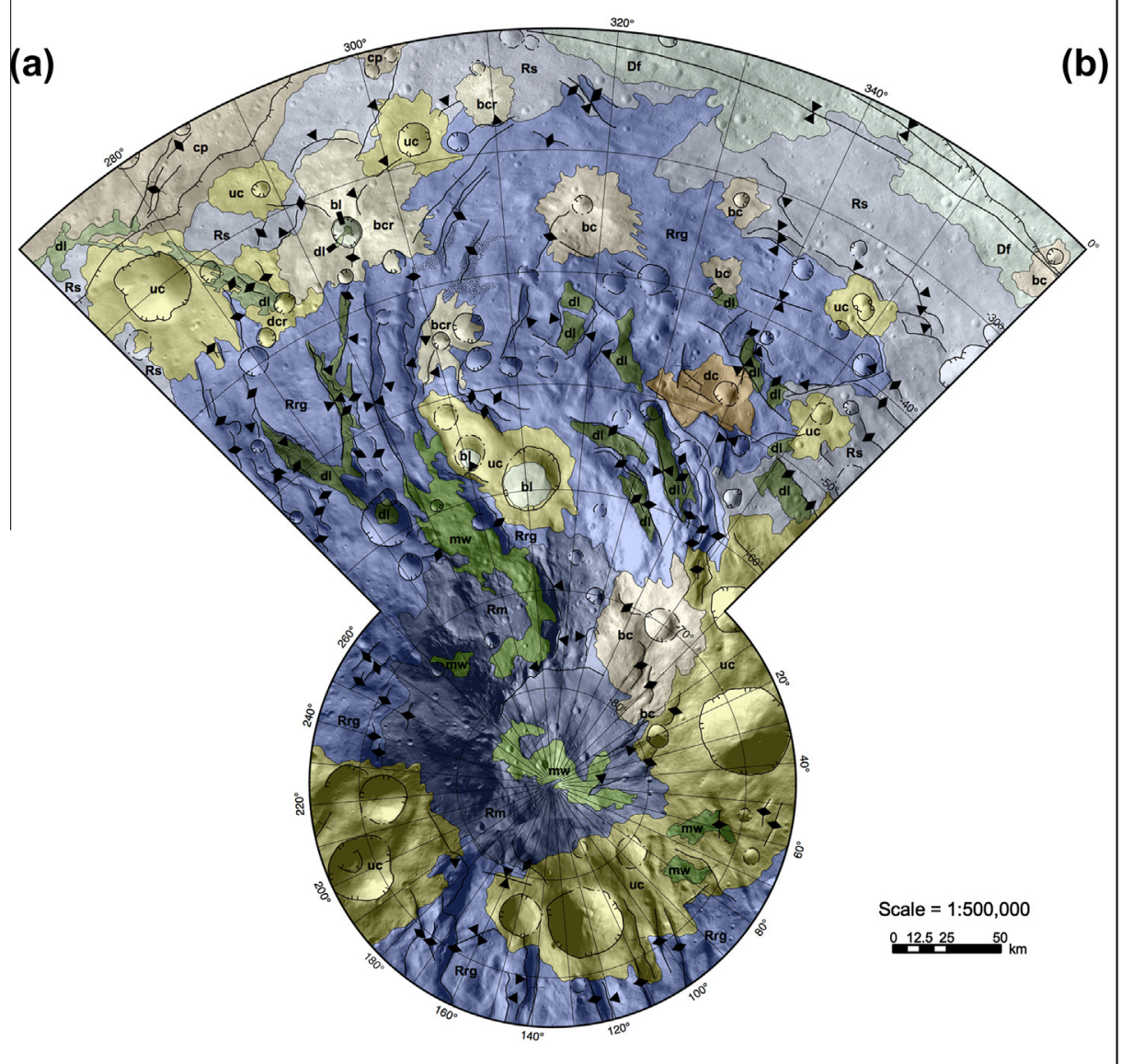

\section{LEGEND}

\section{Linear Features}

$\begin{array}{ll}-- & \begin{array}{l}\text { crest of buried crater } \\ \text { crest of crater rim } \\ \square\end{array} \\ & \text { depression margin } \\ \square & \text { groove } \\ \square & \text { ridge crest (type 1), certain } \\ \square & \text { scarp crest } \\ \square & \text { trough }\end{array}$

\section{Surface Features}

1.7.7.7. dark mantle (orange diffuse ejecta)

secondary crater chain

\section{Geologic Contacts}

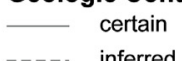

\section{Geologic Units}

\section{Surficial Deposits}

mass wasting material

bright lobate material

dark lobate material

cratered plains material

Impact Crater Materials

bright crater ray material

dark crater ray material

bright crater material

dark crater material

undifferentiatd crater material

Divalia Fossa Formation

Rheasilvia Formation

Rheasilvia smooth terrain

Rheasilvia ridge-and-groove terrain

Rheasilvia mound terrain

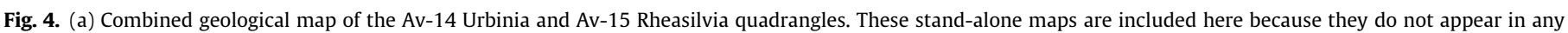

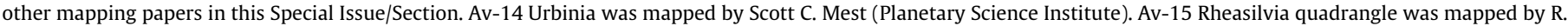
Aileen Yingst (Planetary Science Institute). (b) Combined legend for the Av-14 and Av-15 geologic maps. For description of map units refer to Yingst et al. (in press).

Table 3a

Summary of lessons learned from Vesta quadrangle-based geologic mapping effort.

\begin{tabular}{|c|c|}
\hline Lesson learned & Comment \\
\hline $\begin{array}{l}\text { (1) Geologic mapping efforts provided the team with contextual geologic units } \\
\text { that were critical to making observational decisions during the Nominal } \\
\text { Mission }\end{array}$ & $\begin{array}{l}\text { Global mapping enabled recognition of key units and features that would become } \\
\text { focus of regional mapping }\end{array}$ \\
\hline $\begin{array}{l}\text { (2) Iterative geologic mapping approach enabled mappers to make revisions to } \\
\text { interpretations in real time }\end{array}$ & $\begin{array}{l}\text { This was enabled by Dawn at Vesta mission architecture, with successively lower } \\
\text { orbits and higher resolution imaging phases }\end{array}$ \\
\hline $\begin{array}{l}\text { (3) Traditional mapping techniques did not fully apply to mapping Vesta and had } \\
\text { to be adapted for this body, as well as the Nominal Mission timeline }\end{array}$ & $\begin{array}{l}\text { Vesta's slope-intensive and heavily cratered surface required rethinking of } \\
\text { mapping approaches }\end{array}$ \\
\hline $\begin{array}{l}\text { (4) Coordination of global and regional (quad) mapping among } 15 \text { quads and } 14 \\
\text { mappers was not trivial }\end{array}$ & $\begin{array}{l}\text { A well-defined structure for the mapping group and regular meetings/telecons } \\
\text { required to facilitate work of large group of mappers }\end{array}$ \\
\hline $\begin{array}{l}\text { (5) Some units and feature designations were standardized too early in the } \\
\text { mapping process }\end{array}$ & \\
\hline $\begin{array}{l}\text { (6) Use of pre-determined quadrangle boundaries and scales were an impediment } \\
\text { to contextual understanding and coordination }\end{array}$ & $\begin{array}{l}\text { Quadrangles were assigned prior to arrival of Vesta, so surface geology was not } \\
\text { optimized with skills/interests of mappers }\end{array}$ \\
\hline $\begin{array}{l}\text { (7) Use of cartographic image quadrangles and geologic "sketch maps" were } \\
\text { effective in conveying evolving geologic scenarios to the larger science } \\
\text { community }\end{array}$ & $\begin{array}{l}\text { Fifteen quadrangle "sketch maps" were presented as posters at Fall AGU } 2011 \text { and } \\
\text { LPSC } 2012 \text { meetings }\end{array}$ \\
\hline $\begin{array}{l}\text { (8) Previous geologic mapping experience was critical to the timely production of } \\
\text { useful, objective geologic maps in support of the nominal mission }\end{array}$ & $\begin{array}{l}\text { Whomever leads the geologic mapping effort on a planetary mission must have } \\
\text { experience in planetary geologic mapping, ideally will have published at least one } \\
\text { USGS geologic map }\end{array}$ \\
\hline $\begin{array}{l}\text { (9) Differences in science interest and mapping experience were amplified by large } \\
\text { numbers of mappers and competition among team members to produce papers } \\
\text { quickly, which complicated the production of geologic maps }\end{array}$ & $\begin{array}{l}\text { The more mappers, the more difficult it was to coordinate the mapping. Also, } \\
\text { mappers need to work closely with scientists from other disciplines working on } \\
\text { features in their quadrangles to better coordinate publications. }\end{array}$ \\
\hline
\end{tabular}

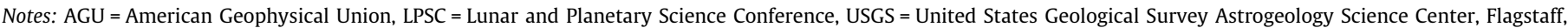
Arizona.

Please cite this article in press as: Williams, D.A., et al. Introduction: The geologic mapping of Vesta. Icarus (2014), http://dx.doi.org/10.1016/ 
Table 3b

Recommendations for future missions on conducting a geologic mapping program during the nominal mission.

Recommendation

(1) Complete draft global geologic map before beginning regional mapping

(2) Identify science drivers from global mapping: Regions, features, terrains that would benefit from larger scale geologic/stratigraphic mapping

(3) Devise a regional/quadrangle-scheme to match science drivers. Match map areas to researchers with requisite science interest and mapping skills. Minimize the number of mappers

(4) Retain generic descriptors for units and features for as long as possible to allow for flexibility in unit delineation and interpretation as well as more consistent coordination between global and regional maps

(5) Develop mapping templates early in Nominal Mission; adapt as necessary as more data becomes available. This includes the GIS package for mapping, conference posters, publication formats, etc.

(6) Use the USGS for guidance on creation of geologic mapping program, including projections, scales, symbols, etc. They can advise on different mapping approaches

(7) Use conference abstracts to document the evolving knowledge of global-regional geology based on geologic mapping during mission timeline

(8) Do not automatically link geologic mapping to peer review manuscript publications

(9) Regional and/or quad-based geologic mapping is a good way to involve graduate students and younger team members

(10) After Nominal Mission ends, consider asking USGS to formally format, review, and publish geologic maps as Special Investigations Map (SIM) series

ronia), Av-4 (Domitia) and Av-5 (Floronia) and produced an integrated geologic map of the northern latitudes, whereas Scully et al. (2014), have focused on structural mapping of features associated with the Saturnalia Fossae Formation, mostly located in quadrangles Av-3 (Caparronia) and Av-4 (Domitia). Blewett et al. (2014) investigate antipodal terrains associated with the Rheasilvia basin, mostly in the Av-1 (Albana) north polar quadrangle.

In the equatorial latitudes, Schaefer et al. (2014) use a combined map of quadrangles Av-6 (Gegania) and Av-7 (Lucaria) to study the dimensions and nature of the equatorial troughs of the Divalia Fossae Formation. Williams et al. (2014) focus on the stratigraphic relations of the large, young fresh craters and associated dark ejecta field found in the Av-8 (Marcia) quadrangle, and Buczkowski et al. (2014) focus on the diversity of units on the highland of Vestalia Terra in Av-9 (Numisia) quadrangle. Garry et al. (2014) have used the geologic map of the Av-10 (Oppia) quadrangle to investigate the stratigraphic relations and the context of high-albedo crater ejecta surrounding Oppia crater, building on the study of Le Corre et al. (2013).

In the southern latitudes of Vesta, there is a variety of crater and ejecta features associated with the Rheasilvia and Veneneia impact basin units. Krohn et al. (2014) use maps of Av-11 (Pinaria) and Av12 (Sextilia) quadrangles to study Vesta's unusual asymmetric craters (sharp rims upslope, subdued rims downslope), while Kneissl et al. (2014) investigate the ejecta of bright, mid-size, young craters and their contact with older basin units in Av-13 (Tuccia) quadrangle. Quadrangle maps of Av-14 (Urbinia) and Av-15 (Rheasilvia), which focus on ridged and grooved and central peak (respectively) units of the Rheasilvia Formation, are discussed in the paper by Yingst et al. (in press), and are also included here as stand-alone maps (Fig. 4a and b).

\section{Lessons learned}

In this section we note the specific lessons learned from our quadrangle-based geologic mapping effort (Table 3a) and make specific recommendations for future missions wanting to conduct a geologic mapping program during their nominal mission (Table $3 \mathrm{~b}$ ).

Although not initially driven by specific science goals for each quadrangle, the quadrangle-based geologic mapping approach that we used throughout the nominal mission provided the team with initial descriptions and interpretations of regional geologic units, building on the work of the global mapping effort (Yingst et al., in press). The mapping process enabled the mappers to revise their interpretations in real time to aid the analysis and interpretation of data returned from other science instruments. However, traditional geologic mapping approaches at global or regional scales do not lend themselves well to a compressed mission timeline.
The needs of the team for rapidly-produced maps meant that coordination between global and regional efforts was non-trivial, and thus, units were standardized earlier in the process than was ideal. For future missions, we recommend that mappers retain more generic descriptors and symbols for as long as possible, until higherresolution data is obtained and descriptions and interpretations can be refined. Early contact and coordination with the U.S. Geological Survey mapping specialists for advice on appropriate USGS mapping approaches and symbols is essential when beginning the process of regional or quadrangle mapping.

For Vesta, the quadrangle mapping began before a first draft global map was completed. A global map would have enabled recognition of the most interesting regions for higher resolution mapping. Also, the quadrangle boundaries were defined and mappers assigned prior to Dawn's arrival at Vesta. As a result, mappers with specific expertise and interests were not necessarily matched up with the most appropriate quadrangle(s), and this inhibited contextual understanding, coordination of mapping effort, and consistency of final map products.

The choice of producing 15 quadrangle geologic maps was based on utilization of the FC cartographic products produced by DLR (Roatsch et al., 2012a), in which these products were similar to cartographic image atlases produced from Cassini data of the saturnian satellites (Roatsch et al., 2008, 2012b). Although a series of 15 early geological "sketch" maps based on these products was useful to display the whole of Vesta's unique surface to the scientific community as a series of posters at scientific conferences during the Nominal Mission, it is now the perspective of the Science Team that attempting to use these same 15 maps as the basis for more detailed geologic mapping studies made the mapping process more difficult. Specifically, key geologic features often crossed quadrangle boundaries, which were rarely crossed by mappers during the mapping process, or during the follow-on analysis. Additionally, differences in science interests and mapping experience were amplified by the large number of mappers (14 different individuals) to cover all 15 quadrangles. Based on the lessons learned from the quadrangle-based regional geologic mapping efforts using Dawn data for the asteroid Vesta, we make the following recommendations for future missions where geologic mapping will be conducted within the compressed mission timeline:

(1) We recommend completing a first draft global geologic map first, identifying the regions where more detailed mapping is justified, then assigning regions to team members, and matching surface features with mappers having the correct expertise, skills and interests to produce quality maps. These regions could use single quadrangles, multiple quadrangles, or parts of quadrangles as defined by the cartographic products. A mapping campaign covering the whole surface of a body with multiple quadrangles should be initiated only if 
such a campaign is justified by the science drivers identified from the first global map. Note that this approach does not preclude work on other topical science studies, including local morphological, compositional, thematic, or geologic mapping. Additionally, it is important that individuals who are assigned quads are experienced mappers, or students with the time and desire to learn how to complete a geologic map.

(2) We recommend decreasing the number of mappers assigned for detailed mapping. This number should be based on the size of the regions mapped, the science rationale for mapping, and/or the amount of detail that is observable in the areas. This could be as few as 2-3, or as high as 6-7 mappers. Any given mapper should be responsible for no more than 2-3 cartographic quadrangles at maximum. Regardless, the number of mappers should be equal to the task at hand, to keep the mapping process more consistent and controlled.

(3) To support coordination of effort, we recommend developing mapping templates early in the nominal mission for ArcGIS $^{\mathrm{TM}}$ projects, conference posters, format of mapping publications, and presenting results. Particularly for missions whose science teams have no experienced geologic mappers, we recommend that the expertise of the USGS Geologic Mapping Program should be obtained if possible, to advise and support mission mapping teams by providing information on (for example) the set up of ArcGISTM projects, approaches for definition and characterization of map units, proper use of mapping symbols (particularly for impact craters and structural features), and development of stratigraphic correlation diagrams.

In general, geologic maps are not necessarily the best way to produce a significant number of peer-reviewed publications quickly, as the geologic mapping process is very slow by nature, and maps do not lend themselves normally to the incremental changes that often occur from publication to publication. That is, once a map is published, it is very hard to justify to reviewers and editors why a new map with only slight changes or a few new conclusions should be published, unless a later mission provides vastly superior data. To mitigate this problem, and recognizing the desire of NASA mission teams to have a high publication rate, we make the following recommendations:

(1) A series of posters at scientific conferences showing image base maps and geologic "sketch maps" can usefully highlight the geology of the body in question to the science team and to the broader community. We recommend utilizing abstracts and conference presentations as the best way to present these very preliminary maps that may be based more on cartography than pure geology, which should be separate from future geologic maps to be included in peerreviewed publications.

(2) Rather than requiring each mapper to produce a peerreviewed paper based on geologic mapping of a cartographic quadrangle, we recommend geologic mapping be based on regional features or process-related science drivers, as a way to facilitate consistency and better scientific coherence. Should the quadrangle-driven mapping process be retained, this approach would also allow other papers to reference any quadrangle papers as needed. Alternately, the quadrangle papers can reference all the previous science papers to argue for the finalized map units and stratigraphy based on all the previous published work. This could also serve to lessen the confusion that occasionally resulted in discussions over unit nomenclature or symbology.
(3) Once topical science questions have been identified from the initial examination of the mission data, geologic mapping is an excellent way for graduate students and younger team members to conduct useful mission-related scientific research and write first-author publications. Supporting the quality science of students and early career researchers is highly worthwhile. Moreover, these individuals have the time (as opposed to instrument leads or senior Team Members) to investigate via detailed mapping interesting features and to study them to a reasonable conclusion. We recommend continuing and strongly supporting this model. Further, we suggest that thematic or topical maps are also excellent vehicles for young team member publications (e.g., a global map of landslides on Vesta, or dark materials, or tectonic features).

(4) When missions with a large number of team members are vying for a small amount of data and everyone needs to publish something, often substantial overlap of effort can occur among those creating regional maps and those focusing on other specific science issues. We found this to cause problems as the second or third wave of team publications began entering review, when for several quadrangles, papers had already been written about key science topics within specific quadrangles before the maps were ready. Conversely, several of our Vesta mappers noted that they thought a robust quadrangle mapping paper could be produced, but not within the nominal mission timeline. We thus recommend that ongoing research be carefully coordinated within the broader science team. The goal should be to assure that research facilitated by geologic mapping is fully supported, without placing undue pressure on team members to define a potential publication solely by a geologic map where such is not warranted.

\section{Acknowledgments}

We thank reviewers James Skinner and Sharon Purdy Wilson and Consulting Editor Peter Thomas for helpful reviews. We thank James Skinner, Trent Hare and Ken Tanaka for helpful discussions regarding the initiation of the Vesta mapping program. We thank Carle Pieters, Ralf Jaumann, Chris Russell, Carol Raymond, and all the members of the Dawn instrument, Science, and Flight Teams for their work operating the spacecraft and returning and processing data of Vesta. DAW, RAY, and WBG were funded from NASA's Dawn at Vesta Participating Scientists Program. The data used in this paper are available from the website http://dawndata.igpp. ucla.edu.

\section{Appendix A}

\section{A.1. Brief summary of lunar-derived chronology}

Determinations of crater size-frequency distributions (CSFDs), i.e., measurements of impact crater diameters and measurementarea sizes, were carried out on LAMO imagery in combination with the digital terrain model described above. We used ESRI's ArcGIS ${ }^{\mathrm{TM}}$ 10 and the software extension CraterTools, which corrects the measurements for errors related to map-projection induced distortions (Kneissl et al., 2011). Using the CraterTools extension, crater diameters are determined in individual local, length-preserving map projections, whereas area sizes are measured in equal-area map projections. Statistical analyses, i.e., plotting of the data in double-logarithmic CSF diagrams, fitting of the production function, and extraction of model ages in Ma or Ga has been done using 
the software CraterStats (Michael and Neukum, 2010). Here, we used the chronology function rev3 and production function rev3 described by Schmedemann et al. (submitted for publication).

Both of these functions are derived from their lunar counterparts but are scaled to the impact conditions at Vesta.

\section{A.1.1. Production function}

The production function describes the theoretically expected CSFD, undisturbed by any geologic process. It excludes event-related cratering processes such as thick ejecta blanketing, secondary cratering, or a vestan self-bombardment by vestoids. Consequently, each CSFD measurement needs a careful interpretation in order to define a reliable crater-diameter fitting range. The production function is defined primarily by the impacting projectile population. Its actual appearance and location in common size-frequency plots (Arvidson et al., 1978) depends on the size scaling between projectile and the respective crater. Scaling the production function from the Moon to Vesta includes two separate steps:

\section{The determination of the SFD of impacting lunar projectiles}

There is a common agreement that Main Belt asteroids are the dominating impactor population in the inner Solar System (Ivanov, 2008; Neukum and Ivanov, 1994; Strom et al., 2005). Mean motion resonances (MMR) with the gravitationally dominating bodies in the Solar System, primarily Jupiter, create zones of instability within the Main Belt. Such zones (i.e., Kirkwood Gaps: see e.g., Wisdom, 1982) are unequally efficient in dynamical exciting contained asteroids, which are eventually expelled from the Main Belt (Gladman et al., 1997). Furthermore, the size-frequency distribution (SFD) of Main Belt asteroids is changing within the Main Belt with respect to the bodies orbital semi-major axis (Tedesco et al., 2005; de Elía and Brunini, 2007). Thus, the SFD of impacting asteroids does not simply represent an average Main Belt distribution but is weighted by the strength of MMR at the asteroids origin within the Belt. In addition, the influence of radiation forces such as the Yarkovsky effect (e.g. Farinella et al., 1998; Chesley et al., 2003; O'Brien and Greenberg, 2005; Bottke et al., 2006; Lowry et al., 2007 ) is slightly changing the orbital parameters of asteroids. This drives the asteroids in a size dependent fashion not only into the MMRs but also into the trajectories of other asteroids. Smaller asteroids are more affected by radiation forces due to their higher surface to mass ratio. Large asteroids such as Vesta remain more or less unaffected by radiation forces. Thus, asteroids, which are preferentially forced into resonances also cross the orbits of other asteroids at respectively higher probabilities. Therefore, it is reasonable to assume a high correlation between the projectiles impacting the Moon and those impacting other bodies in the main asteroid belt such as Vesta. Following this approach, the derivation of the lunar projectile distribution by a backward application of crater scaling laws (Ivanov, 2001), allows for the determination of the weighted SFD of expelled Main Belt asteroids.

\section{The weighted projectile sizes from step 1 are scaled to crater} sizes on the target body, in this case Vesta

For both steps we use revised scaling laws originally described by Ivanov (2001, 2008; Ivanov and Hartmann, 2007). In contrast to $\pi$-group scaling (Housen and Holsapple, 2011) the scaling by Ivanov (2001) require less knowledge of material properties often described by analog materials. Only the contrast of material density between projectile and target is needed. Most of the other required values can be determined by observations (simple/complex transition) or inferred from the targets gravity and size (strength/gravity transition, surface gravity). The impact angle is always held at its most probable value of $45^{\circ}$ (Gilbert, 1893). The last missing scaling value is the impact velocity, which is calculated from statistical analysis of orbit geometries of crossing bodies (Bottke et al., 1994). The same analysis also provides information about the impact probability of such crossing bodies, which is important for the scaling of the lunar chronology function. Because crater sizes are scaled from lunar regolith to vestan regolith, errors due to incorrect material properties are expected to be minuscule. Furthermore, the well investigated lunar cratering record offers one more essential advantage over the direct usage of the Main Belt's SFD, it provides valuable data about the size distribution of projectiles too small to be resolved by ground based Main Belt surveys. The observational completeness of the Main Belt asteroids is at about $2 \mathrm{~km}$ body diameter (July 2012) as has been inferred from the observed body size distribution. This value is decreasing as more objects are identified. A 2-km projectile will cause a $28 \mathrm{~km}$ crater on the Moon and an $18 \mathrm{~km}$ crater on Vesta. The smallest craters used for age determinations on Vesta are about $60 \mathrm{~m}$ in diameter, which corresponds to about 144-m craters on the Moon and a projectile size of about $3.6 \mathrm{~m}$. Thus, the respective small-projectile distribution can be inferred easily from lunar craters, while a pure scaling from observed asteroid body sizes to crater sizes on Vesta requires an extrapolation by a factor of about 550 in order to describe the crater frequencies of small craters used on Vesta. Lunar-like crater distributions have been found on other asteroids such as Gaspra and Ida (Chapman et al., 1996a,b; Neukum and Ivanov, 1994).

\section{A.1.2. Chronology function}

The lunar chronology is derived from ground truth radioisotope age data of lunar rock and soil samples. Due to different interpretation of the data the lunar chronology is heavily debated for decades in the sense whether there was a so-called Late Heavy Bombardment, originally represented by a narrow spike in impact rates around $3.9 \mathrm{Ga}$ (Tera et al., 1974) or whether there has been a smooth decay in impact rates (Neukum and Ivanov, 1994). We use the smooth decay chronology as described by (Neukum and Ivanov, 1994). Morbidelli et al. (2012) found the same smooth decay chronology for the Moon valid for ages younger than $4.1 \mathrm{Ga}$, the proposed onset of the Late Heavy Bombardment.

Utilizing the method of Bottke et al. (1994) we determined the vestan impact probability of crossing bodies larger than $10 \mathrm{~km}$ body diameter (complete observation). This value can be used to determine the linear part of the chronology function. The part representing the exponential decay of projectiles is scaled by the ratio between the linear parts of the lunar and the vestan chronologies. This assumes the same time dependence of changing impact rates between the Moon and Vesta. Essentially, the lunar chronology is shifted in frequency direction according to the expected formation rate of craters $\geqslant 1 \mathrm{~km}$ on Vesta. As discussed above, projectiles forming $1-\mathrm{km}$ craters on Vesta ( $\sim 70 \mathrm{~m}$ projectile diameter) cannot completely be observed in the Main Belt. Crater scaling and the vestan production function are used to infer the respective frequency from statistically determined impact frequencies of the mentioned projectiles larger than $10 \mathrm{~km}$. Crater counts by Schmedemann et al. (submitted for publication) of several key regions on Vesta indicate a positive correlation of major impact events on Vesta and radioisotopic Ar-Ar reset ages of Vesta derived HED meteorites (Bogard, 2011). According to Schmedemann et al. (submitted for publication) the cratering record on Vesta and thus, the vestan chronology, can probably be used up to $\sim 4 \mathrm{Ga}$ surface ages. Beyond that time no trustworthy age information can be obtained from crater frequency measurements. Interestingly also brecciaed HED meteorites show no impact induced reset ages older $\sim 4.25 \mathrm{Ga}$ (Bogard, 2011).

For a more complete discussion of vestan cratering model age estimates using the lunar-derived production and 
chronology functions, please see Schmedemann et al. (submitted for publication).

\section{A.2. Brief summary of asteroid flux-derived chronology}

Determinations of crater size-frequency distributions (CSFDs), i.e., measurements of impact crater diameters and measurementarea sizes, were carried out using established approaches on LAMO image-based crater catalogs that include all agreed upon (by the Dawn Science Team) impact craters on Vesta up to specific sizes (diameters). Cratering model ages for specific regions of Vesta are calculated using a chronology function derived from current understanding of the dynamical history of the main asteroid belt. Unlike the lunar-derived chronology (Schmedemann et al., submitted for publication), which assumes that the rate of impacts in the asteroid belt decayed in the same manner as the rate of impacts inferred from the lunar cratering record, this chronology is based on dynamical models of the asteroid belt that suggests a much different collisional history in the asteroid belt itself. Specifically, this model chronology function (O'Brien et al., submitted for publication) for the asteroid belt assumes that the impact rate in the main asteroid belt was affected by three main processes: (1) a decrease in the impact rate over the first $\sim 100 \mathrm{Myr}$ of Solar System history due to the dynamical depletion of the primordial asteroid belt (Wetherill, 1992; Petit et al., 2001; O'Brien et al., 2007) and/or the decay of leftover planetesimals from the formation of the terrestrial planets; (2) a rapid loss of mass from the asteroid belt around the time of the Late Heavy Bombardment (LHB) resulting from the sweeping of resonances induced by giant planet migration (as described by the Nice Model: Gomes et al., 2005; Morbidelli et al., 2010); and (3) an additional loss of mass by post-LHB chaotic diffusion (Minton and Malhotra, 2010).

This chronology was calibrated using Vesta's surface record of large impact craters, and yields results that are broadly consistent with its ancient surface, as well as other constraints such as the bombardment history of the rest of the inner Solar System and the $\mathrm{Ar}-\mathrm{Ar}$ age distribution of HED meteorites. For instance, the Rheasilvia basin is found to be $\sim 1 \mathrm{Ga}$ (consistent with Schenk et al. (2012) and Marchi et al. (2012a,b)), whereas the most heavily cratered terrain in the northern hemisphere of Vesta is found to be $\sim 4.3 \mathrm{Ga}$ (O'Brien et al., submitted for publication). For details on the asteroid-flux based chronology function, please see O'Brien et al. (submitted for publication).

\section{Appendix B. Supplementary data}

Supplementary data associated with this article can be found, in the online version, at http://dx.doi.org/10.1016/j.icarus.2014.03. 001.

\section{References}

Archinal, B.A. et al., 2011. Report of the IAU Working Group on Cartographic Coordinates and Rotational Elements: 2009. Cel. Mech. Dyn. Astron., vol. 109, no. 2, February, pp. 101-135, doi: http://dx.doi.org/10.1007/s10569-0109320-4.

Arvidson, R. et al., 1978. Standard techniques for presentation and analysis of crater size-frequency data. Reports of planetary geology program, 1977-1978, 338339.

Binzel, R.P., Gaffey, M.J., Thomas, P.C., Zellner, B.H., Storrs, A.D., Wells, E.N., 1997. Geologic mapping of Vesta from 1994 Hubble Space Telescope images. Icarus 128, 95-103.

Blewett, D.T., et al., 2014. Vesta's north polar quadrangle Av-1 (Albana): Geologic map and the nature of the south polar basin antipodes, Icarus, in press, http:/ dx.doi.org/10.1016/j.icarus.2014.03.007.

Bogard, D.D., 2011. K-Ar ages of meteorites: Clues to parent-body thermal histories. Chem. Earth-Geochem. 71 (3), 207-226.

Bottke, W.F., Nolan, M.C., Greenberg, R., Kolvoord, R.A., 1994. Velocity Distributions among Colliding Asteroids. Icarus 107, 255-268.
Bottke Jr., W.F., Vokrouhlický, D., Rubincam, D.P., Nesvorný, D., 2006. The Yarkovsky and Yorp effects: Implications for asteroid dynamics. Annu. Rev. Earth Planet. Sci. 34, 157-191.

Buczkowski, D.L., et al., 2014. The Geology of Vesta Quadrangle Av-9 Numisia: Evaluating the unique geomorphology and physical properties of the Vestalia Terra plateau, Icarus, in press. http://dx.doi.org/10.1016/j.icarus.2014.03.035.

Chapman, C.R. et al., 1996a. Cratering on Ida. Icarus 120, 77-86.

Chapman, C.R., Veverka, J., Belton, M.J.S., Neukum, G., Morrison, D., 1996b. Cratering on Gaspra. Icarus 120, 231-245.

Carr, M.H., Wilhelms, D.E., Greeley, R., Guest, J.E., 1976. Stratigraphy and structural geology. In: Greeley, R., Carr, M.H. (Eds.), A Geological Basis for the Exploration of the Planets. NASA SP-417, pp. 13-32.

Carr, H.R., Saunders, R.S., Strom, R.G., Wilhelms, D.E., 1984. The Geology of the Terrestrial Planets. NASA-SP 469, 317pp.

Carr, M.H., Kirk, R.L., McEwen, A., Veverka, J., Thomas, P., Head, J.W., Murchie, S., 1994. The geology of Gaspra. Icarus 107, 61-71.

Chapman, C.R., Merline, W.J., Thomas, P.C., 1999. Cratering on Mathilde. Icarus 140, $28-33$.

Chapman, C.R., Merline, W.J., Thomas, P.C., Joesph, J., Cheng, A.F., Izenberg, N., 2002. Impact history of Eros: Craters and boulders. Icarus 155, 104-118.

Chesley, S.R. et al., 2003. Direct detection of the Yarkovsky effect by radar ranging to Asteroid 6489 Golevka. Science 302, 1739-1742.

Cochran, A.L., Villas, F., 1998. The changing spectrum of Vesta: Rotationally resolved spectroscopy on surface. Icarus 134, 207-212.

de Elía, G.C., Brunini, A., 2007. Collisional and dynamical evolution of the main belt and NEA population. Astron. Astrophys. 466, 1159-1177.

De Sanctis, M.C. et al., 2011. The VIR spectrometer. Space Sci. Rev. 163, 329-369.

De Sanctis, M.C. et al., 2012a. Spectroscopic characterization of mineralogy and its diversity across Vesta. Science 336, 697-700.

De Sanctis, M.C. et al., 2012b. Detection of widespread hydrated materials on Vesta by the VIR imaging spectrometer on board the Dawn mission. Astrophys. J. 758, L36. http://dx.doi.org/10.1088/2041-8205/758/2/L36.

Ermakov et al., 2013. Modeling of Vesta's interior structure using gravity and shape models form the Dawn mission. Icarus, submitted for publication.

ESRI, 2011. ArcGIS Desktop: Release 10. Environmental Systems Research Institute, Redlands, CA.

Farinella, P., Vokrouhlicky, D., Hartmann, W.K., 1998. Meteorite delivery via Yarkovsky orbital drift. Icarus 132, 378-387.

Feierberg, M.A., Larson, H.P., Fink, U., Smith, H.A., 1980. Spectroscopic evidence for two achondrite parent bodies: Asteroid 349 Dembowska and 4 Vesta. Geochim. Cosmochim. Acta 44, 513-524.

Gaffey, M.J., 1997. Surface lithologic heterogeneity of Asteroid 4 Vesta. Icarus 127, $130-157$.

Garry, W.B., et al., 2014, The geology of the Oppia quadrangle (Av-10) of asteroid (4) Vesta: Determining a relative stratigraphy and relative geologic timescale through geologic mapping, Icarus, submitted for publication.

Gilbert, G.K., 1893. The moon's face: A study of the origin of its features. The Society, Washington.

Gladman, B.J. et al., 1997. Dynamical lifetimes of objects injected into asteroid belt resonances. Science 277, 197-201.

Gomes, R., Levison, H.F., Tsiganis, K., Morbidelli, A., 2005. Origin of the cataclysmic Late Heavy Bombardment period of the terrestrial planets. Nature 435, 466469.

Greeley, R., Carr, M.H., 1976. A Geological Basis for the Exploration of the Planets. NASA SP-417, pp. 13-32.

Hansen, V.L., 2000. Geologic mapping of tectonic planets. Earth Planet. Sci. Lett. 176, 527-542.

Housen, K.R., Holsapple, K.A., 2011. Ejecta from impact craters. Icarus 211, 856-875.

Ivanov, B.A., 2001. Mars/Moon cratering rate ratio estimates. Space Sci. Rev. 96, 87104

Ivanov, B., 2008. Size-frequency distribution of asteroids and impact craters: Estimates of impact rate catastrophic events caused by cosmic objects, In: Adushkin V.V., Nemchinov I.V., (Eds.), Catastrophic Events Caused by Cosmic Objects. Springer, Berlin, pp. 91. ISBN 978-1-4020-6451-7.

Ivanov, B.A., Hartmann, W. K., 2007. Exogenic dynamics, cratering and surface ages. In: Spohn, T. (Ed.), Treatise on Geophysics, vol. 10. Elsevier, pp. 207-242.

Jaumann, R. et al., 2012. Vesta's shape and morphology. Science 336, 687-690.

Kneissl, T., van Gasselt, S., Neukum, G., 2011. Map-projection-independent crater size-frequency determination in GIS environments - New software tool for ArcGISTM. Planet. Space Sci. 59, 1243-1254.

Kneissl, T., et al., 2014, Geology of the Quadrangle Av-13 Tuccia, Vesta Morphology and formation ages of mid-sized post-Rheasilvia craters, Icarus, in press, http://dx.doi.org/10.1016/j.icarus.2014.02.012.

Konopliv, A.S., et al., 2014. The Vesta gravity field, spin pole and rotation period, landmark positions, and ephemeris from the Dawn trackiong and optical data, Icarus, in press, http://dx.doi.org/10.1016/j.icarus.2013.09.005.

Krohn, K., et al., 2014. Mass movement on Vesta at steep scarps and crater rims, Icarus, accepted for publication, http://dx.doi.org/10.1016/j.icarus.2014.03.013.

Le Corre, L, Reddy, V., Nathues, A. Cloutis, E.A., 2011. How to characterize terrains on 4 Vesta using Dawn framing camera color bands? Icarus 216 (2), 376-386.

Le Corre, L. et al., 2013. Olivine or impact melt: Nature of the "orange" material on Vesta from Dawn. Icarus 226, 1568-1594.

Lowry, S.C. et al., 2007. Direct detection of the asteroidal YORP effect. Science 316, $272-274$.

Lugmair, G.W., Shukolyukov, A., 1998. Early Solar System timescales according to ${ }^{53} \mathrm{Mn}-{ }^{53} \mathrm{Cr}$ systematics. Geochim. Cosmochim. Acta 62, 2863-2886. 
Marchi, S. et al., 2010. The cratering history of Asteroid (2867) Steins. Planet. Space Sci. 58, 1116-1123.

Marchi, S. et al., 2012a. The cratering history of Asteroid (21) Lutetia. Planet. Space Sci. 66, 87-95.

Marchi, S. et al., 2012b. The violent collisional history of Asteroid 4 Vesta. Science 336, 690-694.

Marchi, S., et al., 2014. Small crater populations on Vesta, Planet. Space Sci., in press, http://dx.doi.org/10.1016/j.pss.2013.05.005.

Massironi, M. et al., 2012. Geological map and stratigraphy of Asteroid 21 Lutetia. Planet. Space Sci. 66 (1), 125-136.

McCord, T.B., Adams, J.B., Johnson, T.V., 1970. Asteroid Vesta: Spectral reflectivity and compositional implications. Science 168, 1445-1447.

McSween, H.Y., Mittlefehldt, D.W., Beck, A.W., Mayne, R.G., McCoy, T.J., 2011. HED meteorites and their relationship to the geology of Vesta and the Dawn mission. Space Sci. Rev. 163, 141-174.

McSween Jr., H.Y. et al., 2013. Dawn; the Vesta-HED connection; and the geologic context for eucrites, diogenites, and howardites. Meteorit. Planet. Sci. 49 (11), 2090-2104.

Michael, G.G., Neukum, G., 2010. Planetary surface dating from crater sizefrequency distribution measurements: Partial resurfacing events and statistical age uncertainty. Earth Planet. Sci. Lett. 294, 223-229.

Minton, D.A., Malhotra, R., 2010. Dynamical erosion of the asteroid belt and implications for large impacts in the inner Solar System. Icarus 207, 744-757.

Morbidelli, A., Brasser, R., Gomes, R., Levison, H.F., Tsiganis, K., 2010. Evidence from the asteroid belt for a violent past evolution of Jupiter's orbit. Astron. J. 140, 1391-1401.

Morbidelli, A., Marchi, S., Bottke, W.F., Kring, D.A., 2012. A sawtooth-like timeline for the first billion years of lunar bombardment. Earth Planet. Sci. Lett. 355, $144-151$.

Nyquist, L.E., Reese, Y., Wiesmann, H., Shih, C.-Y., Takeda, H., 2001. Dating eucrite formation and metamorphism (abstract). Antarctic Meteorites, National Institute of Polar Research, Tokyo, vol. XXVI, pp. 113-115.

Neukum, G., Ivanov, B.A., 1994. Crater size distributions and impact probabilities on earth from lunar, terrestrial-planet, and asteroid cratering data, In: Tom Gehrels, Matthews, M.S., Schumann, A. (Eds.), Hazards Due to Comets and Asteroids, Space Science Series, University of Arizona Press, Tucson, AZ. pp. 359

O'Brien, D.P., Morbidelli, A., Bottke, W.F., 2007. The primordial excitation and clearing of the asteroid belt-Revisited. Icarus 191, 434-452.

O'Brien, D.P., et al., submitted for publication. Constraining the cratering chronology of Vesta, Planet. Space Sci.

Petit, J., Morbidelli, A., Chambers, J., 2001. The primordial excitation and clearing of the asteroid belt. Icarus 153, 338-347.

O'Brien, D.P., Greenberg, R., 2005. The collisional and dynamical evolution of the main-belt and NEA size distributions. Icarus 178, 179-212.

Pilcher, F., 1979. Circumstances of minor planet discovery. In: Gehrels, T. (Ed.), Asteroids. University of Arizona Press, Tucson, pp. 1130-1154.

Prettyman, T. et al., 2011. Dawn's gamma ray and neutron detector. Space Sci. Rev. $163,371-459$

Prettyman, T.H. et al., 2012. Elemental mapping by Dawn reveals exogenic $\mathrm{H}$ in Vesta's regolith. Science 338, 242-246.

Raymond, C.A. et al., 2013. The crust and mantle of Vesta's southern hemisphere. EPSC Abstracts, vol. 8 (Abstract \#EPSC2013-1002).

Reddy, V., Gaffey, M.J., Kelley, M.S., Nathues, A., Li, J.-Y., Yarbrough, R., 2010. Compositional heterogeneity of Asteroid 4 Vesta's Southern Hemisphere: Implications for the Dawn mission. Icarus 210, 693-706.

Reddy, V. et al., 2012a. Color and albedo heterogeneity of Vesta from Dawn. Science 336, 700-704.

Reddy, V. et al., 2012b. Delivery of dark material to Vesta via carbonaceous chondritic impacts. Icarus 221, 544-559.

Reddy, V. et al., 2013. Comparing Dawn, Hubble Space Telescope, and ground-based interpretations of (4) Vesta. Icarus 226, 1103-1114.

Roatsch, T. et al., 2008. High-resolution Enceladus atlas derived from Cassini-ISS images. Planet. Space Sci. 56, 109-116.

Roatsch, T. et al., 2012a. High resolution Vesta High Altitude Mapping Orbit (HAMO) atlas derived from Dawn framing camera images. Planet. Space Sci. 73, 283286
Roatsch, T. et al., 2012b. High-resolution atlas of Rhea derived from Cassini-ISS images. Planet. Space Sci. 61, 135-141.

Roatsch, T. et al., 2013. High-resolution Vesta Low Altitude Mapping Orbit atlas derived from Dawn framing camera images. Planet. Space Sci. 85, 293-298.

Ruesch, O., et al., 2014. Geologic map of the northern hemisphere of Vesta based on Dawn FC images, Icarus, in press, http://dx.doi.org/10.1016/j.icarus.2014.01. 035.

Russell, C.T., Raymond, C.A., 2011. The Dawn mission to Vesta and Ceres. Space Sci. Rev. 163, 3-23.

Russell, C.T. et al., 2012. Dawn at Vesta: Testing the protoplanetary paradigm. Science 336, 684-686.

Schaefer, M., et al., 2014. Imprint of the Rheasilvia impact on Vesta - Geologic mapping of quadrangles Gegania and Lucaria, Icarus, submitted for publication.

Schenk, P.M. et al., 2012. The geologically recent giant impact basins at Vesta's south pole. Science 336, 694-697.

Schiller, M., Baker, J.A., Bizzarro, M., 2010. ${ }^{26} \mathrm{Al}-{ }^{26} \mathrm{Mg}$ dating of asteroida magmatism in the young Solar System. Geochim. Cosmochim. Acta 74, 48444864.

Schmedemann, N. et al., 2014. The cratering record, chronology and surface ages of (4) Vesta in comparison to smaller asteroids and ages of HED meteorites. Planet. Space Sci., submitted for publication.

Scully, J.E.C., et al., 2014, Saturnalia Fossa group of fossae and additional structures in Vesta's Northern Hemisphere, Icarus, in press, http://dx.doi.org/10.1016/ j.icarus.2014.01.013.

Sierks, H. et al., 2011. The Dawn framing camera. Space Sci. Rev. 163, 263-327.

Srinivasan, G. Goswami, J.N., Bhandari, N., 1999. ${ }^{26} \mathrm{Al}$ in eucrite Piplia Kalan: Plausible heat source and formation chronology. Science 284 1348-1350.

Strom, R.G., Malhotra, R., Ito, T., Yoshida, F., Kring, D.A., 2005. The origin of planetary impactors in the inner solar system. Science 309, 1847-1850.

Sullivan, R.J., Thomas, P.C., Murchie, S.L., Robinson, M.S., 2002. Asteroid geology from Galileo and NEAR Shoemaker data. In: Bottke, W.F., Jr., Cellino, A. Paolicchi, P., Binzel, R.P. (Eds.), Asteroids III. University of Arizona Press, Tucson, pp. 31-350.

Tanaka, K.L. et al., 2010. Planetary Geologic Mapping Handbook. <http:// astrogeology.usgs.gov/Projects/PlanetaryMapping/>

Tera, F., Papanastassiou, D.A., Wasserburg, G.J., 1974. Isotopic evidence for a terminal lunar cataclysm. Earth Planet. Sci. Lett. 22, 1-21.

Tedesco, E.F., Cellino, A., Zappal, V., 2005. The Statistical Asteroid Model. I. The Main-Belt Population for Diameters Greater than 1 Kilometer. Astron. J. 129 2869-2886.

Thomas, P.C., Binzel, R.P., Gaffey, M.J., Storrs, A.D., Wells, E.N., Zellner, B.H., 1997a Impact excavation on Asteroid 4 Vesta: Hubble Space Telescope results. Science 277, 1492-1495.

Thomas, P.C., Binzel, R.P., Gaffey, M.J., Zellner, B.H., Storrs, A.D., Wells, E., 1997b. Vesta: Spin pole, size, and shape from HST images. Icarus 128, 88-94.

Veverka, J., Belton, M., Klassen, K., Chapman, C., 1994. Galileo's encounter with 951 Gaspra: Overview. Icarus 107, 2-17.

Wetherill, G.W., 1992. An alternative model for the formation of the asteroids Icarus 100, 307-325.

Wilhelms, D.E., 1990. Geologic mapping. In: Greeley, R., Batson, R.M. (Eds.) Planetary Mapping. Cambridge Univ. Press, New York, pp. 208-260.

Williams, J.G., 1989. Asteroid family identifications and proper elements. In: Binzel R.P. et al. (Eds.), Asteroids II. University of Arizona Press, Tucson, pp. 10341072.

Williams, D.A., et al., 2014, The geology of the Marcia quadrangle of asteroid Vesta: Assessing the effects of large, young craters, Icarus, in press, http://dx.doi.org/ 10.1016/j.icarus.2014.01.033.

Wilson, L., Keil, K., 1996. Volcanic eruptions and intrusions on Asteroid 4 Vesta. J. Geophys. Res. 101, 18927-18940.

Wisdom, J., 1982. The origin of the Kirkwood gaps - A mapping for asteroidal motion near the 3/1 commensurability. Astron. J. 87, 577-593.

Yingst, R.A. et al., 2011. A preliminary global geologic map of Vesta based on Dawn survey orbit data. Eos (Fall Suppl.). American Geophysical Union. Abstract P43B0248.

Yingst, R.A. et al., 2014. Geologic mapping of Vesta. Planet. Space Sci., in press 